\title{
Perfil sociodemográfico e interesses profissionais de graduandos de Odontologia do Centro Universitário de Patos
}

\author{
Mabel de Figueiredo Rocha Silva*; Josefa Aparecida Alves Ribeiro**; Gigliana Maria Sobral \\ Cavalcante**; Samara Cirilo Feitosa Germano**; Suyene de Oliveira Paredes** $^{* *}$
}

* Graduada em Odontologia, Centro Universitário de Patos

** Professora, Curso de Odontologia, Centro Universitário de Patos

Recebido em 28/08/2018. Aprovado em 22/12/2019.

\begin{abstract}
RESUMO
Este estudo objetivou avaliar o perfil sociodemográfico dos graduandos em Odontologia do Centro Universitário de Patos (UNIFIP), bem como conhecer seus interesses e expectativas em relação à formação e exercício profissional. Participaram desta pesquisa os 414 estudantes matriculados no curso, no segundo semestre letivo de 2017. Empregou-se um questionário contendo questões objetivas e subjetivas e foram utilizados testes estatísticos para associar as variáveis sociodemográficas com os turnos de estudo. A maioria dos graduandos era do sexo feminino $(68,1 \%)$, na faixa etária de até 29 anos $(93 \%)$ e solteiros $(84,1 \%)$. A principal razão diante da escolha do curso foi vocação $(47,8 \%)$. As áreas de atuação de maiores interesses foram cirurgia e traumatologia $(28,8 \%)$, seguida pela ortodontia $(19,8 \%)$. A análise comparativa demonstrou que no turno noturno havia predominância de graduandos do sexo masculino $(\mathrm{p}=0,041)$, com idade igual ou superior a 30 anos $(\mathrm{p}=0,001)$, casados ou divorciados $(\mathrm{p}<0,003)$, que residiam com cônjuges e/ou filhos $(\mathrm{p}<0,001)$, que possuíam renda e contribuíam para o sustento de suas famílias $(\mathrm{p}<0,001)$, trabalhavam mais de 20 horas semanais $(p<0,001)$, cursaram todo o ensino médio em escola pública $(p=0,001)$ e residiam em outros municípios ( $\mathrm{p}<0,001)$. A curto prazo, $70 \%$ dos pesquisados pretendiam iniciar curso de pós-graduação e atuar na Estratégia Saúde da Família (ESF) (44\%). A médio e longo prazo 68,6\% pretendia atuar em clínica privada, com menor interesse em atuar na ESF (19,3\%). Em conclusão, existem diferenças significativas no perfil dos estudantes do Curso de Odontologia diurno e noturno do Centro Universitário de Patos.

Descritores: Educação Superior. Estudantes de Odontologia. Mercado de Trabalho. Educação em Odontologia.
\end{abstract}




\section{INTRODUÇÃO}

A Odontologia é uma área que passa por constantes mudanças, especialmente nos últimos anos, fazendo com que a sociedade tenha uma visão diferenciada da profissão. Isto também é comum no que se refere à formação do profissional em Odontologia, bem como a sua adaptação ao mercado de trabalho, que se renova com muita frequência ${ }^{1}$.

É crescente o número de instituições superiores que oferecem cursos de Odontologia. No sistema e-MEC encontram-se atualmente credenciados e em atividade 538 cursos. Portanto à medida que surgem novos cursos de Odontologia, aumenta expressivamente o número de cirurgiõesdentistas formados que são inseridos no mercado de trabalho. Os profissionais recém-formados, muitas vezes, enfrentam situações que não eram comuns durante o seu cotidiano acadêmico. Isto pode causar uma sensação de insegurança, fazendo com que os mesmos, sintam-se incapazes de enfrentar uma carreira profissional ${ }^{2,3}$.

A Odontologia possui uma característica de profissão liberal. Por este fato, torna-se uma área cada vez mais procurada e crescente. É responsabilidade da instituição de ensino superior, adotar métodos de ensino crítico e reflexivo contribuindo com uma formação profissional ampla. Portanto, os cursos de graduação devem realizar avaliações periódicas relacionadas à qualidade do ensino, exigência e satisfação a respeito do próprio curso. Além disso, os cursos de Odontologia deverão formar cirurgiões-dentistas clínicos gerais, mas com uma formação ampla, com base biológica, científica, técnica, social e humanística. Estes profissionais devem estar aptos para exercer as funções que lhes competem em serviços públicos e privados, bem como entender os desafios do mercado de trabalho e serem capazes de exercer liderança em sua comunidade ${ }^{4}$.

O Curso de Odontologia do Centro Universitário de Patos (UNIFIP) foi criado no município de Patos, localizado no Estado da Paraíba. A primeira turma ingressante foi matriculada no ano de 2008, com estrutura curricular prevendo integralização do curso em quatro anos, época em que a instituição era credenciada como Faculdades Integradas de Patos. A partir de 2013 o curso passou a ser regido por um novo fluxograma, estruturado em dez períodos, sendo necessário que o discente finalize sua graduação em, no mínimo, cinco anos. O Projeto Pedagógico do Curso (PPC), frente à sua organização didático-pedagógica, expõe no capítulo "Perfil do Egresso" a incorporação de uma visão mais social, crítica e humanitária na formação do profissional graduado em Odontologia ${ }^{5}$.

Patos situa-se na mesorregião do sertão e possui extensão territorial de $473.056 \mathrm{Km}^{2}$ e população composta por 107.790 habitantes, de acordo com os dados da contagem populacional de 20106. Por estar situado no centro do Estado da Paraíba, o município possui uma localização privilegiada, exercendo forte influência geoeconômica entre os municípios paraibanos circunvizinhos, como também, entre alguns municípios mais próximos pertencentes a outras unidades federativas, tais como Rio Grande do Norte, Pernambuco e Ceará.

Considerando-se a importância sociodemográfica do município de Patos nos setores comercial, de serviços e educação, e diante da viabilidade de acesso existente, considera-se que os cursos de graduação, entre eles o de Odontologia do UNIFIP, reúnem um número expressivo de estudantes oriundos e/ou residentes em diversas localidades adjacentes ou próximas a este município. Neste entendimento, o curso de Odontologia configura-se por apresentar uma população de discentes heterogênea em relação à procedência, sendo estes provenientes das mais diversas localidades e dos diferentes contextos sociodemográficos.

Diante do exposto, este estudo propõe avaliar o perfil sociodemográfico dos estudantes de 
graduação em Odontologia do UNIFIP, a partir de uma análise comparativa entre os turnos de estudo, bem como conhecer seus interesses em relação à formação e exercício profissional.

\section{METODOLOGIA}

Este estudo exploratório, de natureza descritiva e analítica, foi submetido ao Comitê de Ética em Pesquisa do UNIFIP, recebendo parecer de aprovação número CAAE: 75835717.8.00005181. Para a execução do mesmo foram seguidas todas as diretrizes e normas propostas pela Resolução $\mathrm{n}^{\circ} 510$ de 07 de abril de 2016, do Conselho Nacional de Saúde (CNS), a qual regulamenta a ética em pesquisas envolvendo seres humanos ${ }^{7}$.

Trata-se de um estudo censitário, portanto, foram incluídos todos os graduandos do Curso de Odontologia matriculados e cursando o segundo semestre letivo do ano de 2017 que autorizaram sua participação por meio da assinatura do Termo de Consentimento Livre e Esclarecido (TCLE). Para os discentes que fossem menores de dezoito anos de idade, elaborou-se o Termo de Assentimento do Menor, além do TCLE direcionado ao responsável.

Os dados foram coletados por uma única pesquisadora devidamente treinada para a aplicação do questionário. O mesmo foi respondido pelo pesquisado, em sala de aula, sem que houvesse interferência por parte da pesquisadora. O questionário, elaborado pela equipe de investigadoras, foi adaptado dos estudos de Ponte $(2012)^{8}$ e Sousa et al. (2017) ${ }^{9}$ e foi revisado por duas pesquisadoras da instituição proponente, externas à equipe de pesquisa. $\mathrm{O}$ instrumento de coleta de dados foi dividido em duas seções: a primeira referiu-se ao perfil sociodemográfico do graduando, e a segunda seção foi estruturada em torno das variáveis referentes às expectativas em relação ao curso e ao exercício profissional.

Com relação à análise dos dados, foram calculadas frequências absolutas e percentuais para as variáveis sociodemográficas, econômicas e relacionadas aos interesses profissionais dos graduandos de Odontologia ${ }^{10}$. Todas as análises foram conduzidas usando o software Statistical Program for Social Science versão 20.0 (SPSS for Windows, SPSS, Inc., Chicago, IL, USA). Utilizaram-se os testes estatísticos - Teste do Quiquadrado e Exato de Fisher - para associar as variáveis sociodemográficas com os turnos de estudo (matutino ou noturno) escolhidos pelos graduandos. Os testes empregados foram considerados significativos com $\mathrm{p}<0,05$.

\section{RESULTADOS}

Do total de 578 graduandos regularmente matriculados no segundo semestre letivo do ano de 2017, 414 concordaram em participar. A tabela 1 mostra a distribuição dos estudantes de acordo com as características sociodemográficas, econômicas e situação no curso. A maioria era do sexo feminino (282; 68,1\%), tinha até 29 anos de idade (385; $93,0 \%)$, autodeclarou-se branca $(244 ; 59,1 \%)$ e era solteira $(348 ; 84,1 \%)$. Outra opção de resposta dada pelos participantes em relação ao estado civil foi a de união estável. Além disso, a maior parte relatou residir com pais ou parentes em casa ou apartamento (208; 50,2\%), bem como que não tinha renda, sendo os gastos financiados pela família ou outras pessoas (306; 73,9\%). Observou-se que mais da metade dos alunos que participaram do estudo era do $4^{\circ}, 5^{\circ}, 6^{\circ}$ ou $7^{\circ}$ período $(218 ; 52,7 \%$ ), estando regularmente matriculado no turno noturno $(208 ; 50,2 \%)$.

A tabela 2 mostra a distribuição dos estudantes de acordo com as razões de ter escolhido cursar Odontologia, dificuldades enfrentadas e apontamentos em relação às qualificações de um bom cirurgião-dentista. A maioria destacou que escolheu cursar Odontologia por vocação (198; 47,8\%). Aqueles que responderam a opção "outras" relataram ter escolhido cursar Odontologia por desejo de ajudar o próximo. No entanto, a principal dificuldade enfrentada foi relacionada à questão financeira/alto custo da mensalidade e dos materiais 
Tabela 1. Distribuição dos estudantes de acordo com as características sociodemográficas, econômicas e situação no curso

\begin{tabular}{|c|c|c|}
\hline Variáveis & $\mathbf{n}$ & $\%$ \\
\hline \multicolumn{3}{|l|}{ Sexo $[n=414]$} \\
\hline Masculino & 132 & 31,9 \\
\hline Feminino & 282 & 68,1 \\
\hline \multicolumn{3}{|l|}{ Idade $[n=414]$} \\
\hline$\leq 29$ anos & 385 & 93,0 \\
\hline$\geq 30$ ou mais & 29 & 7,0 \\
\hline \multicolumn{3}{|l|}{ Cor autodeclarada $[n=413]$} \\
\hline Branca & 244 & 59,1 \\
\hline Negra & 15 & 3,6 \\
\hline Parda & 144 & 34,9 \\
\hline Amarela & 10 & 2,4 \\
\hline \multicolumn{3}{|l|}{ Estado civil [ $n=414]$} \\
\hline Solteiro & 348 & 84,1 \\
\hline Casado & 58 & 14,0 \\
\hline Separado/desquitado/divorciado & 5 & 1,2 \\
\hline Outro & 3 & 0,7 \\
\hline \multicolumn{3}{|l|}{ Condição de moradia do aluno [ $n=414]$} \\
\hline Reside sozinho & 64 & 15,5 \\
\hline Reside com pais ou parentes & 208 & 50,2 \\
\hline Reside com cônjuge e/ou filhos & 66 & 15,9 \\
\hline Reside com outras pessoas & 76 & 18,4 \\
\hline \multicolumn{3}{|l|}{ Situação de renda que melhor descreve o caso do aluno [n=414] } \\
\hline Não tem renda, os gastos são financiados pela família ou outras pessoas & 306 & 73,9 \\
\hline Tem renda, mas recebe ajuda da família ou de outras pessoas & 70 & 16,9 \\
\hline Tem renda e se sustenta totalmente & 11 & 2,7 \\
\hline Tem renda, se sustenta e contribui para o sustento da família & 21 & 5,1 \\
\hline Tem renda, se sustenta e é o principal responsável pelo sustento da família & 6 & 1,4 \\
\hline \multicolumn{3}{|l|}{ Renda mensal familiar [ $n=412]$} \\
\hline Menos do que 3 salários mínimos & 138 & 33,5 \\
\hline 4 a 6 salários mínimos & 213 & 51,7 \\
\hline 7 ou mais salários mínimos & 61 & 14,8 \\
\hline \multicolumn{3}{|l|}{ Situação de trabalho do aluno [ $n=414]$} \\
\hline Não está trabalhando & 317 & 76,6 \\
\hline Trabalha eventualmente & 32 & 7,7 \\
\hline Trabalha até 20 horas semanais & 26 & 6,3 \\
\hline Trabalha mais de 20 horas semanais & 39 & 9,4 \\
\hline \multicolumn{3}{|l|}{ Tipo de instituição que o aluno cursou o ensino médio [n=414] } \\
\hline Todo em escola pública & 161 & 38,9 \\
\hline Todo em escola privada & 207 & 50,0 \\
\hline Parte em escola pública e parte em escola privada & 46 & 11,1 \\
\hline \multicolumn{3}{|l|}{ Teve de mudar de município, estado ou país para realizar o curso $[n=414]$} \\
\hline Sim, de município & 208 & 50,2 \\
\hline Sim, de estado & 72 & 17,4 \\
\hline Não & 134 & 32,4 \\
\hline \multicolumn{3}{|l|}{ Local de moradia atualmente $[n=414]$} \\
\hline Patos-PB & 212 & 51,2 \\
\hline Em outro município & 148 & 35,7 \\
\hline Parte da semana em Patos/PB e parte em outro município & 54 & 13,0 \\
\hline \multicolumn{3}{|l|}{ Período $[n=414]$} \\
\hline $1^{\circ}$ ao $3^{\circ}$ período & 86 & 20,8 \\
\hline $4^{\circ}$ ao $7^{\circ}$ período & 218 & 52,7 \\
\hline $8^{\circ}$ ao $10^{\circ}$ período & 110 & 26,6 \\
\hline \multicolumn{3}{|l|}{ Turno $[n=414]$} \\
\hline Matutino & 206 & 49,8 \\
\hline Noturno & 208 & 50,2 \\
\hline
\end{tabular}


(107; 40,8\%). Em relação às qualificações que melhor descrevem um bom cirurgião-dentista, as mais assinaladas/apontadas pelos estudantes foram: ter competência/experiência/compromisso/ser responsável $(99 ; 25,1 \%)$, ser um profissional humanizado $(68 ; 17,3 \%)$ e ter ética $(50 ; 12,7 \%)$. As áreas pelas quais os alunos despertaram maior interesse foram: cirurgia oral menor/cirurgia e traumatologia bucomaxilofacial/implantodontia (115; 28,8\%), ortodontia $(79 ; 19,8 \%)$ e reabilitação oral: dentística/estética/prótese (77; 19,2\%).

A curto prazo, a maioria tinha a pretensão de iniciar um curso de especialização/aperfeiçoamento
(290; 70,0\%), bem como de atuar em clínica privada na condição de autônomo (201; 48,6\%). A médio e longo prazo, a maioria destacou que pretendia atuar em clínica privada na condição de autônomo (284; $68,6 \%)$. Um dado que chama atenção é que foi constatado menor interesse em atuar na Estratégia de Saúde da Família (ESF) considerando as perspectivas a médio e longo prazo $(80 ; 19,3 \%)$, em comparação com as perspectivas a curto prazo (182; $44,0 \%)$. Por fim, verificou-se que os estudantes esperavam demorar entre 1 e 5 anos após a colação de grau para conseguir montar um consultório (294; $71,2 \%)$.

Tabela 2. Distribuição dos estudantes de acordo com as razões de ter escolhido cursar Odontologia, dificuldades enfrentadas e apontamentos em relação às qualificações de um bom cirurgião-dentista

\begin{tabular}{|c|c|c|}
\hline Variáveis & $\mathbf{n}$ & $\%$ \\
\hline \multicolumn{3}{|l|}{ Razão pela qual escolheu cursar Odontologia [ $n=414]$} \\
\hline Vocação & 198 & 47,8 \\
\hline Ser autônomo (não ter patrão, definir meus honorários) & 32 & 7,7 \\
\hline Influência da família e/ou amigos & 50 & 12,1 \\
\hline $\begin{array}{l}\text { Perspectiva de boa remuneração (profissão rentável) / Oferece grandes chances de } \\
\text { crescimento profissional/ status profissional }\end{array}$ & 96 & 23,2 \\
\hline Existência de faculdade local & 6 & 1,4 \\
\hline Não passei em outro vestibular & 16 & 3,9 \\
\hline Outros & 16 & 3,9 \\
\hline \multicolumn{3}{|l|}{ Primeira dificuldade enfrentada [ $n=262]$} \\
\hline Financeira/alto custo da mensalidade e materiais & 107 & 40,8 \\
\hline Deslocamento/transporte/mudar de cidade & 73 & 27,9 \\
\hline $\begin{array}{l}\text { Concentração nos estudos/retornar a estudar depois de muito tempo/grade curricular } \\
\text { complicada }\end{array}$ & 16 & 6,1 \\
\hline Ausência dos familiares/morar sozinho & 34 & 13,0 \\
\hline Relacionamento com professores/funcionários/amigos de curso/ pressão psicológica & 3 & 1,1 \\
\hline Conciliar trabalho e estudo ou responsabilidade familiar / Ter pouco tempo para os estudos & 27 & 10,3 \\
\hline Não tenho afinidade com o curso & 2 & 0,8 \\
\hline \multicolumn{3}{|l|}{ Primeira qualificação do bom cirurgião-dentista [n=394] } \\
\hline Profissional atualizado & 45 & 11,4 \\
\hline Ter vocação & 38 & 9,6 \\
\hline Profissional humanizado & 68 & 17,3 \\
\hline Conhecimento (teórico, conhecimentos integrados, habilidade técnica/hab. práticas) & 94 & 23,9 \\
\hline Ter competência/experiência/compromisso/ser responsável & 99 & 25,1 \\
\hline Ter ética & 50 & 12,7 \\
\hline \multicolumn{3}{|l|}{ Primeira área de escolha [n=399] } \\
\hline Reabilitação oral (dentística/estética/prótese) & 77 & 19,2 \\
\hline Diagnóstico oral (estomatologia/radiologia) & 3 & 0,8 \\
\hline Cirurgia oral menor/traumatologia bucomaxilofacial/implantodontia & 115 & 28,8 \\
\hline Endodontia & 53 & 13,3 \\
\hline Periodontia & 12 & 3,0 \\
\hline Odontopediatria/saúde coletiva/cariologia/odontologia preventiva & 56 & 14,0 \\
\hline Ortodontia & 79 & 19,8 \\
\hline Pacientes com necessidades especiais & 1 & 0,3 \\
\hline Odontologia legal & 3 & 0,8 \\
\hline
\end{tabular}


A tabela 3 mostra a análise comparativa entre os estudantes regularmente matriculados nos turnos matutino e noturno de acordo com as características sociodemográficas. Observou-se que, em relação ao sexo, o curso apresenta maior proporção de homens no turno noturno e de mulheres no turno matutino $(\mathrm{p}=0,041)$. Em relação à idade, no turno matutino a maioria apresenta idade até 29 anos, e uma maior proporção de estudantes com idade igual ou superior a 30 anos no turno noturno ( $\mathrm{p}=0,001)$. No turno matutino, há uma maior proporção de pessoas solteiras, e no turno noturno maior proporção de pessoas casadas ( $\mathrm{p}=0,003$ ). Os estudantes do turno matutino residem sozinhos em casa ou apartamento, enquanto aqueles matriculados no turno noturno residem com cônjuges e/ou filhos $(\mathrm{p}<0,001)$. Quanto à renda, os estudantes do turno matutino relataram não possuir renda própria, tendo desta forma os gastos financiados por familiares ou outras pessoas. Em contrapartida, no turno noturno, há um maior número de alunos que trabalham e que, inclusive, contribuem com o sustento da família ( $p<0,001)$. Sobre a condição de trabalho, verificouse que a maioria dos graduandos do turno matutino não exerce nenhum tipo de trabalho, já no turno noturno esta proporção é diferente, apresentando inclusive alunos que trabalham mais de 20 horas semanais $(\mathrm{p}<0,001)$.

\section{DISCUSSÃO}

O processo de mudança que envolve os rumos do ensino odontológico, provavelmente relaciona-se à adequação dos planos pedagógicos pelas instituições de ensino superior. Neste contexto, o Curso de Odontologia do UNIFIP adotou, em seu currículo, disciplinas que se relacionam à formação integral do discente, capacitando-o para atuação em todos os níveis de atenção à saúde. Além disso, o referido curso, por meio de seus estágios curriculares, busca inserir os graduandos na realidade social de Patos/PB e demais municípios circunvizinhos, de mesmos anseios e realidades sociais. Isto possibilita aos mesmos desenvolverem ações de prevenção, promoção, proteção e reabilitação da saúde, tanto em nível individual quanto coletivo, assim como preconizam as Diretrizes Curriculares Nacionais que regulamentam a organização dos cursos de Graduação em Odontologia das instituições do Sistema de Educação Superior do País².

Neste cenário, é possível perceber que as mudanças não acontecem apenas no ensino propriamente dito, mas também em relação ao perfil daqueles que fazem a escolha pela área. Estudos demonstraram que houve um processo chamado de feminização, ou seja, um maior número de mulheres na Odontologia, o que a descaracteriza como uma profissão masculina, como foi historicamente considerada. Esta preferência também pode ser explicada pelas características femininas delicadas que as mulheres possuem para desenvolver trabalhos manuais ${ }^{11-15}$. Confirmando este processo de feminização, a avaliação do perfil sociodemográfico dos participantes deste estudo, mostrou que $68,1 \%$ dos graduandos eram do sexo feminino. Este achado corrobora os resultados de outro estudo realizado com 98 alunos matriculados neste mesmo curso, do primeiro ao oitavo período, no turno matutino, em 2013. Naquele momento, a maior parte da amostra $(68,4 \%)$ também era do sexo feminino ${ }^{16}$. Além disso, estudos recentes que avaliaram perfil de egressos e estudantes do último ano, em localidades de diferentes macrorregiões do país, revelaram predomínio de mulheres entre os graduandos nos cursos de Odontologia ${ }^{17-20}$.

Em relação à idade dos participantes, pode-se afirmar que o curso apresentou uma população de graduandos jovens. A maioria $(93,0 \%)$ dos estudantes matriculados apresentou idade menor ou igual a vinte e nove anos. Outros estudos já comprovaram a maior existência de jovens nos cursos de Odontologia ${ }^{21-23}$. 
Tabela 3. Análise comparativa entre os estudantes regularmente matriculados nos turnos matutino e noturno de acordo com as características sociodemográficas

\begin{tabular}{|c|c|c|c|c|c|c|c|}
\hline \multirow{3}{*}{ Variáveis } & \multicolumn{4}{|c|}{ Turno } & & & \\
\hline & \multicolumn{2}{|c|}{ Diurno } & \multicolumn{2}{|c|}{ Noturno } & \multicolumn{2}{|c|}{ Total } & \multirow[t]{2}{*}{ p-valor } \\
\hline & n & $\%$ & $\mathbf{n}$ & $\%$ & $\mathbf{n}$ & $\%$ & \\
\hline \multicolumn{8}{|l|}{ Sexo } \\
\hline Masculino & 56 & 42,4 & 76 & 57,6 & 132 & 100,0 & \multirow{2}{*}{$0,041^{(\mathrm{a}) *}$} \\
\hline Feminino & 150 & 53,2 & 132 & 46,8 & 282 & 100,0 & \\
\hline \multicolumn{8}{|l|}{ Idade } \\
\hline$\leq 29$ anos & 200 & 51,9 & 185 & 48,1 & 385 & 100,0 & \multirow[b]{2}{*}{$0,001^{(\mathrm{a}) *}$} \\
\hline$\geq 30$ ou mais & 6 & 20,7 & 23 & 79,3 & 29 & 100,0 & \\
\hline \multicolumn{8}{|l|}{ Estado civil } \\
\hline Solteiro & 186 & 53,4 & 162 & 46,6 & 348 & 100,0 & \multirow{4}{*}{$0,003^{(\mathrm{b}) *}$} \\
\hline Casado & 18 & 31,0 & 40 & 69,0 & 58 & 100,0 & \\
\hline Separado/desquitado/ & 1 & 20,0 & 4 & 80,0 & 5 & 100,0 & \\
\hline Outro & 1 & 33,3 & 2 & 66,7 & 3 & 100,0 & \\
\hline \multicolumn{8}{|l|}{ Condição de moradia } \\
\hline Reside sozinho & 40 & 62,5 & 24 & 37,5 & 64 & 100,0 & \multirow{4}{*}{$<0,001^{(\mathrm{a}) *}$} \\
\hline Reside com pais ou parentes & 102 & 49,0 & 106 & 51,0 & 208 & 100,0 & \\
\hline Reside com cônjuge e/ou filhos & 19 & 28,8 & 47 & 71,2 & 66 & 100,0 & \\
\hline Reside com outras pessoas, & 45 & 59,2 & 31 & 40,8 & 76 & 100,0 & \\
\hline \multicolumn{8}{|l|}{ Situação de renda } \\
\hline $\begin{array}{l}\text { Sem renda, financiado por } \\
\text { outros }\end{array}$ & 172 & 56,2 & 134 & 43,8 & 306 & 100,0 & \multirow{5}{*}{$<0,001^{(\mathrm{b}) *}$} \\
\hline $\begin{array}{l}\text { Tem renda, mas recebe ajuda da } \\
\text { família ou outros }\end{array}$ & 23 & 32,9 & 47 & 67,1 & 70 & 100,0 & \\
\hline Tem renda e se sustenta & 5 & 45,5 & 6 & 54,5 & 11 & 100,0 & \\
\hline $\begin{array}{l}\text { Tem renda, contribui com o } \\
\text { sustento próprio e família }\end{array}$ & 4 & 19,0 & 17 & 81,0 & 21 & 100,0 & \\
\hline $\begin{array}{l}\text { Tem renda, se sustenta e sustenta } \\
\text { família }\end{array}$ & 2 & 33,3 & 4 & 66,7 & 6 & 100,0 & \\
\hline \multicolumn{8}{|l|}{ Situação de trabalho } \\
\hline Não está trabalhando & 183 & 57,7 & 134 & 42,3 & 317 & 100,0 & \multirow{4}{*}{$<0,001^{(\mathrm{a}) *}$} \\
\hline Trabalha eventualmente & 8 & 25,0 & 24 & 75,0 & 32 & 100,0 & \\
\hline Trabalha até 20 h semanais & 8 & 30,8 & 18 & 69,2 & 26 & 100,0 & \\
\hline Trabalha+ de 20h semanais & 7 & 17,9 & 32 & 82,1 & 39 & 100,0 & \\
\hline \multicolumn{8}{|l|}{ Instituição ensino médio } \\
\hline Todo em escola pública & 62 & 38,5 & 99 & 61,5 & 161 & 100,0 & \multirow{3}{*}{$0,001^{(\mathrm{a}) *}$} \\
\hline Todo em escola privada & 118 & 57,0 & 89 & 43,0 & 207 & 100,0 & \\
\hline $\begin{array}{l}\text { Parte em escola pública e parte } \\
\text { em escola privada }\end{array}$ & 26 & 56,5 & 20 & 43,5 & 46 & 100,0 & \\
\hline \multicolumn{8}{|l|}{ Local de moradia } \\
\hline Patos/PB & 123 & 58,0 & 89 & 42,0 & 212 & 100,0 & \multirow{3}{*}{$<0,001^{(\mathrm{a}) *}$} \\
\hline Em outro município & 51 & 34,5 & 97 & 65,5 & 148 & 100,0 & \\
\hline $\begin{array}{l}\text { Parte da semana em Patos e parte } \\
\text { em outro município }\end{array}$ & 32 & 59,3 & 22 & 40,7 & 54 & 100,0 & \\
\hline
\end{tabular}

Nota:(a) Teste qui-quadrado de Pearson; (b) Teste exato de Fisher; * $\mathrm{p}<0,05$.

Observou-se também que a maioria não possuía renda própria, tendo seus gastos custeados por familiares, o que provavelmente tem estreita ligação com a ocupação dos estudantes, já que 
76,6\% não trabalhavam. Em 2016, outro estudo realizado somente com discentes do turno matutino comprovou percentual um pouco maior, sendo representado por $86,7 \%{ }^{16}$. A renda mensal familiar da maioria dos pesquisados situava-se entre quatro a seis salários mínimos, o que pode explicar o fato da metade dos estudantes ter cursado o ensino médio em instituições privadas. Uma condição socioeconômica favorável pode proporcionar maior facilidade para adquirir artifícios de complementação de estudo, assim como permite maior dedicação no desenvolvimento de atividades, para ampliar o conhecimento ${ }^{24}$.

Sobre a escolha da Odontologia como profissão, neste estudo, evidenciou-se um expressivo número de participantes respondendo "vocação" como motivo de decisão. No entanto, outras justificativas foram citadas, como o fato de acreditar ser a Odontologia um campo de atuação com perspectivas de boa remuneração, oferecendo chances de crescimento profissional e status profissional. Um estudo realizado em Minas Gerais comprovou que dentre as diversas razões de escolhas citadas pelos graduandos, estavam a de conseguirem ascensão social e econômica, e este relato estava ligado ao desejo de poder manter um bom padrão de vida, com comodidade, organização de horários e autonomia financeira ${ }^{25}$. Outra pesquisa realizada com concluintes em Odontologia da Universidade Estadual da Paraíba, mostrou que a realização pessoal e profissional levaram os estudantes à escolha do curso, além do interesse destes em atuar na comunidade ${ }^{18}$.

Apesar dos participantes deste estudo apresentar uma renda familiar satisfatória, foi relatada pela maioria, a dificuldade financeira como principal obstáculo enfrentado, frente aos gastos com mensalidade e custos com materiais e instrumentais. Este pode ser considerado um obstáculo para o ingresso e permanência de estudantes nos cursos de Odontologia, especialmente entre aqueles cujas famílias possuem renda mensal mais baixa ${ }^{23}$. Sugere-se, portanto, ser uma das causas de evasão, visto que tais custos certamente comprometem uma parte significativa das despesas mensais. Além disso, outras razões também foram citadas dentre as dificuldades, tais como deslocamento/transporte/mudar de cidade. Certamente, estas razões relacionam-se ao fato de que uma parte significativa dos estudantes residia em outros municípios.

No tocante às perspectivas profissionais após a conclusão do curso, em um curto prazo de tempo, foi possível perceber que quase metade dos pesquisados $(48,6 \%)$ manifestaram o desejo de exercer suas atividades em clínicas privadas como autônomos. Um estudo realizado em Belo Horizonte mostrou semelhanças com o presente estudo, pois nas três universidades estudadas naquele município, os graduandos também desejavam trabalhar em setores privados 9 . Semelhantemente, um expressivo número de estudantes concluintes de uma universidade pública de São Paulo revelou o desejo de trabalhar em clínicas ou consultórios privados como autônomos ${ }^{20}$. Contrariamente, $80 \%$ dos concluintes da Universidade Federal de Santa Catarina desejaram associar o trabalho em consultório privado com o serviço público, por questões de estabilidade e complementação de renda $^{19}$.

Neste estudo, os estudantes desejavam atuar na ESF (44\%) e 70\% pretendiam realizar cursos de especialização ou aperfeiçoamento. Em um período considerado de médio e longo prazo, a opção de escolha de trabalho em clínica privada como profissionais autônomos, foi ainda maior (68\%), bem como cresceu o interesse de seguir a carreira acadêmica (43,2\%). No entanto, o interesse em atuar no serviço público e na ESF foi consideravelmente menor $(19,3 \%)$ quando comparado com interesses a curto prazo. Neste sentido, este achado mostrou-se semelhante ao apresentado em um estudo realizado em dois cursos de Odontologia, um público e um privado no Estado da Bahia, no qual o interesse em 
trabalhar em serviço público foi inicialmente maior, no entanto, a longo prazo, esse desejo diminuiu significativamente ${ }^{26}$.

Mesmo sendo obrigatório o registro no Conselho Regional de Odontologia (CRO) para atuar profissionalmente, uma pequena parcela dos estudantes $(3,1 \%)$ respondeu não querer a inscrição imediatamente após a formatura. Este achado mostrou concordância com outro estudo, no qual um número reduzido de estudantes $(3,9 \%)$ afirmaram que não desejavam cadastrar-se no $\mathrm{CRO}^{19}$.

A perspectiva de salário para os próximos cinco anos situou-se entre quatro a seis salários mínimos, aproximando-se da pretensão salarial dos estudantes de uma faculdade particular de Belo Horizonte, bem como dos estudantes da Universidade Federal de Pernambuco, que apresentaram uma perspectiva de renda inicial de dois mil e quinhentos a cinco mil reais ${ }^{3,22}$. Um estudo com egressos formados ao longo de dez anos, em uma instituição pública do Piauí, comprovou satisfação financeira dos pesquisados, com maior número de profissionais atuando no interior $\mathrm{e}$ relatando média salarial de até dez salários mínimos ${ }^{17}$.

Ao comparar os alunos por turno, perceberam-se variáveis estatisticamente associadas, evidenciando diferenças importantes no perfil dos acadêmicos de Odontologia do UNIFIP. Foi possível identificar que o turno noturno apresentou uma maioria significativa de estudantes do sexo masculino, com idade igual ou superior a trinta anos e uma maioria de casados em relação aos estudantes do turno matutino. Esses resultados são diferentes dos encontrados em um estudo realizado com estudantes do curso noturno da Faculdade de Odontologia da Universidade Federal do Rio Grande Sul, composto, em sua maioria, por mulheres com idades entre 17 e 22 anos e solteiras ${ }^{14}$.

Outras diferenças significativas foram percebidas entre os alunos dos dois turnos. Notou-se que em relação à condição de moradia, situação de renda e de trabalho, os estudantes do turno noturno em sua maioria responderam residir com cônjuges e/ou filhos, possuir renda e contribuir para o sustento de suas famílias, além de trabalharem mais de vinte horas semanais, e ainda residirem em outros municípios. Em contrapartida, o turno matutino apresentou uma maior população de estudantes que residiam sozinhos, não possuíam renda, não trabalhavam, residiam em Patos/PB ou então passam a semana na referida localidade e os fins de semana em seus municípios. Essas características mostram que não existem apenas diferenças significantes entre o perfil sociodemográfico, mas também diferentes realidades de vida para cursar esta graduação. $\mathrm{O}$ fato dos acadêmicos do turno noturno se deslocarem diariamente de outros munícipios até a localidade onde está situada a faculdade, faz com que os mesmos gastem mais horas em deslocamento quando comparado aos discentes do turno matutino. Isto pode refletir, por sua vez, em horas a mais de estudos para os graduandos que gastam pouco tempo para chegar à instituição de ensino.

Pode-se destacar que muitos dos graduandos que estudam no período da noite eram trabalhadores e contribuíam com os sustentos de suas famílias, percebendo-se, assim, a necessidade de conciliar uma jornada diária entre estudo e trabalho. Considerando-se a relação entre trabalho e estudo, essa pode ser considerada como um fator de dificuldade para tais estudantes. Um estudo de caráter qualitativo, objetivando identificar os motivos de retenção e evasão dos estudantes do curso, pôde identificar que os graduandos trabalhadores revelaram que fatores como cansaço, sono, esgotamento e o pouco tempo para se dedicarem aos estudos, são motivos que interferem no desempenho acadêmico. Já os professores, percebiam que o rendimento destes alunos, diminuía à medida que se aproximava do término das aulas, interferindo no rendimento dos mesmos. No entanto, os docentes percebiam quão dedicados 
eram estes estudantes em sala de aula, aproveitando ao máximo os momentos de explicações ${ }^{27}$.

Diante do exposto, o presente estudo comprovou a divergência entre os perfis dos graduandos de Odontologia do UNIFIP, que estudam nos turnos matutino ou noturno. As instituições de ensino superior que oferecem a opção ao estudante de cursar a graduação em um turno específico, identificadas, principalmente, em instituições privadas, oportunizam aos indivíduos que trabalham (responsáveis por seu sustento e, por vezes, sustento de toda família) acesso à educação superior na área da saúde, entre elas a Odontologia. Além disso, as diferenças estatísticas evidenciadas são importantes para que coordenadores e educadores possam compreender situações como, por exemplo, desempenhos acadêmicos diferentes, assim como participações e ausências em programas de monitoria, pesquisa e extensão, as quais podem estar relacionadas com esta heterogeneidade de perfil. Por fim, o Curso de Odontologia do UNIFIP, funcionando em um município que, apesar de localizado no interior do estado da Paraíba, exerce forte influência geográfica e econômica sobre diversas outras localidades interioranas desta e de outras unidades federativas, acaba atraindo estudantes dos mais variados contextos sociodemográficos.

\section{CONCLUSÃO}

Conclui-se que os estudantes envolvidos neste estudo eram, em sua maioria, do sexo feminino, solteiros e com idade igual ou menor do que vinte $\mathrm{e}$ nove anos, os quais responderam terem feito a escolha pelo curso por possuir vocação. Os mesmos demonstraram interesse em atuar em clínica privada como profissionais autônomos bem como manifestaram o desejo de realizar cursos de pósgraduação. A pretensão salarial para os próximos cinco anos foi de quatro a seis salários mínimos. Quanto às áreas de atuação da Odontologia, cirurgia e ortodontia foram apontadas como as de maior interesse pelos estudantes.

Ao comparar os estudantes por turno, evidenciaram-se diferenças importantes no perfil. No turno noturno, havia predominância de graduandos do sexo masculino, com idade igual ou superior a 30 anos, bem como maior proporção de casados ou divorciados, residindo com cônjuges e/ou filhos, que possuíam renda e contribuíam para o sustento de suas famílias, trabalhavam mais de 20 horas semanais, que cursaram o ensino médio em escola pública e residiam em outros municípios.

\section{ABSTRACT \\ Sociodemographic profiles and professional interests of Patos University Center undergraduate dentistry students}

This study aimed to evaluate the sociodemographic profiles of undergraduate dentistry students at the Patos University Center (UNIFIP), and to learn their interests and expectations in relation to training and professional practice. The study included 414 students enrolled in the second semester of 2017. A questionnaire containing objective and subjective questions, and statistical tests were used to associate sociodemographic variables with the school shift attended. The undergraduates were mostly female $(68.1 \%)$, aged up to 29 years $(93 \%)$ and single $(84.1 \%)$. The main reason given for choosing the course was vocation $(47.8 \%)$. The areas of greatest interest were surgery and traumatology $(28.8 \%)$, followed by orthodontics (19.8\%). Comparative analysis revealed a predominance of male students $(\mathrm{p}=0.041)$ attending the night school shift, aged 30 or over $(p=0.001)$, married or divorced ( $\mathrm{p}<0.003$ ), who lived with spouses and/or children $(\mathrm{p}<0.001)$, with income and contributing to the support of their families ( $\mathrm{p}$ $<0.001$ ), working more than 20 hours per week ( $\mathrm{p}<0.001)$, exclusively attending public high schools $(\mathrm{p}=0.001)$ and residing in other municipalities $(\mathrm{p}<0.001)$. For the short term, $70 \%$ of respondents intended to attend postgraduate courses and work within the Family Health Strategy (FHS) (44\%). For the medium 
and long term, $68.6 \%$ intended to work in a private clinic, presenting less interest in working with the FHS (19.3\%). In conclusion, significant differences were revealed in the profiles of day and night dentistry course students at the Patos University Center.

Descriptors: Education, Higher. Students, Dental. Job Market. Education, Dental.

\section{REFERÊNCIAS}

1. Ferreira NP, Ferreira AP, Freire MCM. Mercado de trabalho na Odontologia: contextualização e perspectivas. Rev Odontol UNESP. 2013; 42(4):304-09.

2. Brasil. Ministério da Educação. Conselho Nacional de Educação. Câmara de Educação Superior. Resolução CNE/CES 3/2002. Diretrizes Curriculares Nacionais do Curso de Graduação em Odontologia. [online]. Diário Oficial da União, Brasília, 4 de março de 2002. Seção 1, p.10. (Acesso em 25 ago. 2017). Disponível em http://portal.mec.gov.br/sesu/ arquivos/pdf/0302Odontologia.pdf

3. Souza LRF, Silva GD, Oliveira CAS, Zocratto KBF. Mercado de trabalho: perspectivas dos alunos do curso de Odontologia de uma faculdade particular de Belo Horizonte. Odontol Clín-Cient. 2015; 14(3):707-12.

4. Silva AC, Franco MM, Costa EL, Assunção HRM, Costa JF. Perfil do acadêmico de odontologia de uma Universidade pública. Rev Pesq Saude. 2011;12(1):22-6.

5. Projeto Pedagógico de Curso PPC: Odontologia (Bacharelado). Centro Educacional de Ensino Superior de Patos LTDA. Faculdades Integradas de Patos. Núcleo docente estruturante. Patos: FIP, 2016.

6. Brasil. Ministério do Planejamento, Orçamento e Gestão. Instituto Brasileiro de Geografia e Estatística. Sinopse dos resultados do Censo 2010. Brasília: IBGE; 2010 (Acesso em 10 jun. 2017). Disponível em: http://www.censo2010.ibge.gov.br/sinopse/W
ebService

7. Brasil. Conselho Nacional de Saúde. Resolução $N^{\circ}$ 510, de 7 de abril de 2016. Dispõe sobre as normas aplicáveis a pesquisas em Ciências Humanas e Sociais (CHS). Diário Oficial da União. Poder Executivo, Brasília, DF, 24 maio 2016. Seção 1, n. 98, p. 44-46.

8. Ponte TM. Perfil psicológico e interesses profissionais de estudantes de odontologia. Tese (Doutorado em odontologia social). Faculdade de Odontologia da Universidade de São Paulo. São Paulo, 2012.

9. Sousa JES, Maciel LK B, Oliveira CAS, Zocratto KBF. Mercado de trabalho em Odontologia: perspectivas dos estudantes concluintes de faculdades privadas no município de Belo Horizonte, Brasil. Rev ABENO. 2017; 17(1):74-86.

10. Larson R, Farber B. Estatística Aplicada. 6 . ed. São Paulo: Pearson Prentice Hall, 2016.

11. Costa SM, Durães SJ, Abreu MHNG. Feminização do curso de odontologia da Universidade Estadual de Montes Claros. Ciênc Saúde Coletiva. 2010;15(1):1865-73.

12. Leite DFBM, Trigueiro M, Martins IMCLB, Lima Neto TJ, Santos MQ. Perfil socioeconômico de 253 graduandos de Odontologia de uma instituição privada em João Pessoa-PB em 2011. J Health Sci Inst. 2012; 30(2):117-119.

13. Oliveira DL, Souza ES, Batista FJN, Alves JV, Yarid SD. Perfil do aluno de Odontologia da Universidade Estadual do Sudoeste da Bahia UESB. Rev Saúde Com. 2013; 9(3):169-78.

14. Souza JM, Souza MG, Toassi RFC. Democratização ao serviço de educação pública a partir do REUNI: o curso noturno de Odontologia da Universidade Federal do Rio Grande do Sul. Rev PPGE UNESC. 2015; $4(1): 1-21$.

15. Hertl J, Santos DH, Bruzamolin CD, Marques FR. Avaliação socioeconômica e expectativa 
profissional de alunos recém-ingressos na faculdade de odontologia. Rev Gestão \& Saúde. 2017; 16(1):36-43.

16. Granja GL, Santos JTL, Mariz RC, Araki AT, Souza SV, Nunes JMFF, Fonseca FRA Perfil dos estudantes de graduação em Odontologia: motivações e expectativas da profissão. Rev ABENO. 2016; 16(4):107-13.

17. Ferraz MAAL, Nolêto MSC, Martins LLN, Bandeira SRL, Portela SGC, Pinto PHV, et al. Perfil dos egressos do curso de Odontologia da Universidade Estadual do Piauí. Rev ABENO. 2018; 18(1):56-62.

18. Querino JPFO, Peixoto LR, Sampaio GAM. Perfil dos concluintes de odontologia da Universidade Estadual da Paraíba. Rev ABENO. 2018; 18(1):170-81.

19. Silva CV, Spiger V, Amante CJ. Perfil e expectativas profissionais de concluintes do curso de graduação em odontologia da Universidade Federal de Santa Catarina. Rev ABENO. 2018; 18(3):35-42.

20. Cayetano MH, Gabriel M, Tavares J, Araújo ME, Martins JS, Michel-Crosato E, Carrer FCA. O perfil dos estudantes de Odontologia é compatível com o mercado de trabalho no serviço público de saúde brasileiro? Rev ABENO. 2019; 19(2):2-12.

21. Latreille AC, Sobrinho SM, Warmling AMF, Ribeiro DM, Amante CJ. Perfil socioeconômico dos graduandos em odontologia da Universidade Federal de Santa Catarina. Rev ABENO. 2015; 15(1):86-96.

22. Marques MD, Souza CA, Pazos CTC, Amaral
DS, Vieira EG, Campos WCS, Carvalho EJA. Expectativas dos estudantes de Odontologia quanto ao futuro profissional. Rev ABENO. 2015; 15(3):60-8.

23. Santos BRM, Gonzales PS, Carrer FCA, Araújo ME. Perfil e expectativas dos ingressantes da Faculdade de Odontologia da USP: uma visão integrada com as diretrizes curriculares nacionais e o sistema único de saúde. Rev ABENO. 2015; 15(1):28-37.

24. Machado DC, Souto DM, Freitas CHSM, Forte FDS. Odontologia como escolha: perfil de graduandos e perspectiva para o futuro profissional. Rev ABENO. 2010; 10(2):27-34.

25. Costa SM, Durães SJA, Abreu MHNG, Bonan PRF, Vasconcelos M. Motivos de escolha da Odontologia: vocação, opção ou necessidade? Arq Odontol. 2010;46(01):28-37.

26. Matos MS, Tenório RM. Expectativas de estudantes de Odontologia sobre o campo de trabalho odontológico e o exercício profissional. Rev Bras Pesqui Saúde. 2011; 13(4):10-21.

27. Lamers JMS, Santos BS, Toassi RFC. Retenção e evasão no ensino superior público: estudo de caso em um curso noturno de odontologia. Educ Rev. 2017; 33:01-26.

\section{Correspondência para:}

Suyene de Oliveira Paredes email: suyparedes@ hotmail.com Rua Evangelina Rodrigues de Sousa, 15

Bairro Maternidade 58700-000 Patos/PB 